\title{
Macroepizoísmo em Libinia ferreirae (Crustacea, Brachyura, Majidae) ${ }^{1}$
}

\author{
Vanessa C. Winter ${ }^{2} \&$ Setuko Masunari ${ }^{3}$
}

1. Contribuição número 1563 do Departamento de Zoologia, Setor de Ciências Biológicas da Universidade Federal do Paraná.

2. Departamento de Zoologia, Setor de Ciências Biológicas, UFPR, Caixa Postal 19020,81531-990 Curitiba, PR. (vw_bio@pop.com.br)

3. Curso de Pós-graduação em Zoologia UFPR, bolsista de produtividade do CNPq. (setmas@ufpr.br)

\begin{abstract}
Macroepizoites on Libinia ferreirae (Crustacea, Brachyura, Majidae). A study of the distribution of the macroepizoites was carried out on a population of the spider crab Libinia ferreirae Brito Capello, 1871 from the Southern Brazilian coast. Crabs were obtained from shrimps and fishes by-catch. They were measured, and their macroepizoites were identified and counted. The following sessile macroepizoites were registered: Calliactis tricolor (Lesueur, 1817) (Cnidaria); Actiniaria (Cnidaria); Arca sp. (Mollusca); Ostreidae (Mollusca); Acanthodesia tenuis (Desor, 1848) (Bryozoa); Cirripedia and two species of Gammaridea (Crustacea). The sea anemone C. tricolor was the most frequent species and probably it is used as a mechanism of camouflage by crabs. Macroepizoites on $L$. ferreirae are related to its age or size, therefore, bigger or older crabs had greater incidence of macroepizoites. However, the density of macroepizoites is about three per crab. There is not a relationship between macroepizoism and sex of the host, but ovigerous females use this resource more frequently than non-ovigerous ones. Due to larger setting area, macroepizoites colonize mainly the carapace of the host; bryozoans predominate in hosts' pereiopods.
\end{abstract}

KEYWORDS. Camouflage, spider crab, macroepizoites, epizoism.

RESUMO. Um estudo de distribuição dos macroepizóicos foi realizado numa população do caranguejo-aranha Libinia ferreirae Brito Capello, 1871 proveniente do litoral dos estados do Paraná e de Santa Catarina. O material biológico foi obtido junto aos pescadores, e faz parte do rejeito de pesca. Os caranguejos foram mensurados e os macroepizóicos identificados e contados. Os seguintes macroepizóicos sésseis foram registrados: Calliactis tricolor (Lesueur, 1817) (Cnidaria); Actiniaria (Cnidaria); Arca sp. (Mollusca); Ostreidae (Mollusca); Acanthodesia tenuis (Desor, 1848) (Bryozoa); Cirripedia e duas espécies tubícolas de Gammaridea (Crustacea). Além destes organismos ocorreram dois tubos desabitados e quatro animais vágeis. A anêmona $C$. tricolor foi a espécie mais abundante e freqüente, sendo, provavelmente, utilizada como mecanismo de camuflagem pelo caranguejo. O macroepizoísmo em L. ferreirae está relacionado com a idade ou tamanho do caranguejo, tendo maior incidência naqueles mais velhos ou de maior porte. Entretanto, a densidade dos macroepizóicos por caranguejo se mantém em torno de três. Não há relação entre o macroepizoísmo e o sexo do hospedeiro; somente fêmeas ovígeras utilizam desse recurso mais freqüentemente do que as não-ovígeras. Devido à maior área de fixação, os macroepizóicos colonizam principalmente a carapaça do caranguejo, enquanto nos pereiópodos há predominância de Bryozoa.

PALAVRAS-CHAVE. Camuflagem, caranguejo-aranha, macroepizóico, epizoísmo.

Epizoísmo é caracterizado como uma associação entre dois organismos, o hospedeiro e o epizóico. Esta interação pode ser facultativa ou obrigatória, do tipo parasitismo. A associação pode não afetar qualquer um dos componentes, entretanto, hospedeiros e epizóicos podem obter benefícios ou sofrer desvantagens (Wahl, 1989 apud BECKER, 1996).

BECKER (1996), em um estudo abrangente de 47 espécies de Malacostraca, incluindo 41 de Decapoda, encontrou macroepizóicos (animais sésseis e algas) em apenas nove espécies (cerca de 2,2\%) de caranguejos. Somente Hyastenus sp. (Majidae) apresentou a superfície da carapaça densamente colonizada por nove macroepizóicos. Ainda, segundo o autor, os caranguejos são pobremente colonizados por epizóicos devido aos mecanismos de defesa, tais como muda, limpeza e produção de substâncias químicas.

A família Majidae é bastante conhecida devido ao hábito de seus membros apresentarem organismos epizóicos. Uma peculiaridade desta família é a presença de cerdas em forma de gancho no seu exoesqueleto, onde organismos sésseis e biodetritos são fixados deliberadamente. Este comportamento pode ter origem na estocagem de alimento no exoesqueleto, porém, a maioria das espécies desta família decoram o corpo com epizóicos para camuflagem contra predadores (WICKSTEN, 1980, 1993).

Algumas espécies de Majidae mostram uma sofisticada adaptação ao ambiente através do epizoísmo. Esses caranguejos adaptam a aparência da sua carapaça ao substrato que habitam, para torná-los menos evidentes aos predadores (WICKSTEN, 1993; FERNÁNDEZ et al., 1998). Microphrys bicornutus Latreille, 1825 utiliza duas espécies de algas, tanto para camuflagem como para a alimentação. Dependendo da abundância de uma determinada alga na natureza, a dieta deste caranguejo pode mudar, com preferência por uma ou outra espécie de alga. Entretanto, experimentos em laboratório demonstraram que a preferência por alimento não pode ser explicada satisfatoriamente sem considerar o comportamento de camuflagem (KILAR \& Lou, 1986).

A espécie do epizóico varia de acordo com o ambiente e, portanto, o habitat é um fator determinante para o epizoísmo. Para caranguejos cujos juvenis vivem em águas rasas e os adultos em profundidades elevadas, a frequiência de epibiose é mais intensa nos juvenis. Além disso, como a camuflagem dos juvenis é feita com algas, ela é mais intensa nas estações de primavera e verão, quando estas algas são mais abundantes (FERNÁNDEZ et al., 1998). Caranguejos que adquirem a cor da alga por 
ingestão da mesma fixam algas da mesma cor com mais frequiência do que algas de cor diferente (WILSON, 1987).

A relação entre a natureza do substrato onde ocorre um caranguejo hospedeiro e a diversidade e a densidade dos epizóicos ainda é um assunto controverso. Enquanto Williams \& Moyse (1988) consideram o exoesqueleto de Neolithodes grimaldi Milne-Edwards \& Bouvier, 1894 (Anomura) como um raro e precioso substrato compacto para Cirripedia, num habitat a $1.545 \mathrm{~m}$ de profundidade, BECKER (1996) sugere que os caranguejos habitantes de substratos rochosos têm maior probabilidade de portar epizóicos, enquanto os de substrato inconsolidado teriam a possibilidade de evitar o assentamento de epizóicos pela abrasão provocada pelo atrito entre o exoesqueleto e a areia ou lodo, durante o mergulho ou movimento no sedimento.

De uma forma geral, caranguejos maduros que sofrem muda menos freqüentemente, ou que têm a muda da puberdade como a última do ciclo de vida, abrigam maior diversidade e densidade de espécies de epizóicos (Mori \& MANConi, 1990; Abelló \& MacPherson, 1992; SHIELDS, 1992; Dick et al., 1998; FERNÁNDEZ et al., 1998).

Os macroepizóicos mais comumente registrados sobre o exoesqueleto de caranguejos são, na maioria, sésseis e pertencem aos seguintes grupos animais: Porifera, Cnidaria, Polychaeta, Turbellaria, Bryozoa, Mollusca, Cirripedia e Ascidiacea (Mori \& MANCONI, 1990; Abelló \& MACPHERSON, 1992; BECKER, 1996; DicK et al., 1998; FERNÁNDEZ et al., 1998). Espécies que necessitam de substrato estável (ausência de muda do hospedeiro), como Bryozoa e Cirripedia, são mais freqüentes em caranguejos maduros (FERNÁNDEZ et al., 1998).

A associação mutualística entre a anêmona-do-mar Antholoba achates (Drayton, 1846) e o caranguejo Libinia spinosa Milne Edwards, 1834, provenientes do litoral da Argentina, foi estudada por AcuÑa et al. (2003). Este mutualismo restringe-se aos juvenis das anêmonas e tem função de camuflagem, visto que as dietas do hospedeiro e do epizóico são totalmente diferentes.

Várias espécies de Majidae, como Pugettia sp., Epialtoides sp. e Simocarcinus sp., fixam organismos sobre toda a superfície dorsal da carapaça e dos pereiópodos. Outras, como Pugettia producta (Randall, 1840), Epialtus minimus Lockington, 1877 e Acanthonyx petiveri Milne Edwards, 1834 colocam o material somente no rostro (WICKSTEN, 1993).

Sobre Libinia ferreirae Brito Capello, 1871 (Majidae), NogueIRA JunIOR \& HADDAD (2005) trataram da associação entre os juvenis deste caranguejo e as medusas Lychnorhiza lucerna Haeckel, 1880 ocorrentes no litoral do estado do Paraná. Este caranguejo apresenta distribuição geográfica no Atlântico Ocidental, da Venezuela ao Brasil, e neste, do estado do Pará até Santa Catarina. Vive preferencialmente em fundos lodosos e pode ser encontrado do entremarés até 35 metros de profundidade (Melo, 1996). A superfície da sua carapaça é rugosa devido à presença de cérdulas e dos cerca de 30 espinhos tuberculados que lhe dão um aspecto irregular. Entretanto, não há cerdas recurvadas ou em forma de gancho que propiciariam uma ancoragem de epizóicos.

Um estudo descritivo dos macroepizóicos e dos vestígios dos mesmos ocorrentes sobre L. ferreirae obtidos no litoral dos estados do Paraná e de Santa Catarina foi realizado com o objetivo de estudar as características morfológicas, como sexo e tamanho do caranguejo hospedeiro, e verificar sua influência na distribuição dos macroepizóicos.

\section{MATERIAL E MÉTODOS}

Os exemplares de L. ferreirae foram obtidos do rejeito de pesca de camarão e de peixe, junto aos pescadores dos municípios de Itapoá, em Santa Catarina (treze amostragens) e de Guaratuba, no Paraná (quatro amostragens), de junho a outubro de 2004. As redes utilizadas variaram de 1 a $7 \mathrm{~cm}$ de abertura de malha. As amostragens dos caranguejos foram feitas em duas etapas: a primeira, realizada em junho e julho, consistiu de uma coleta seletiva de exemplares portadores de macroepizóicos; a segunda foi realizada de agosto a outubro, na qual todos os caranguejos, com ou sem macroepizóicos, foram obtidos. Esta última amostragem foi destinada ao estudo da taxa de macroepizoísmo. Entretanto, na análise da distribuição dos macroepizóicos, os caranguejos com macroepizóicos colhidos na primeira etapa também foram incluídos. Adicionalmente, espécimes juvenis comensais da medusa L. lucerna foram acrescentadas no estudo de distribuição de macroepizóicos em L.ferreirae.

Os caranguejos foram conservados em freezer até o seu processamento. De cada exemplar, foi anotado o sexo e medida a largura da carapaça. Os macroepizóicos foram contados e identificados e os tubos vazios aderidos ao exoesqueleto foram registrados. A localização dos macroepizóicos e dos tubos no corpo do caranguejo foi anotada, discriminando-se as seguintes partes: rostro, carapaça e pereiópodos.

Alguns organismos vágeis presentes na superfície do corpo de L. ferreirae foram anotados e listados, porém, devido à possibilidade de uma eventual contaminação pela fauna bentônica durante a coleta, somente as espécies sésseis foram analisadas.

Dentre os macroepizóicos sésseis, foram observados tubos pergaminosos, alguns contendo Nereidae e outros, Gammaridea. Como aqueles são animais vágeis (poliquetas) enquanto estes são tubícolas (anfípodas), somente estes últimos foram analisados no presente estudo, tendo sido representados por Gammaridea sp. 1 e sp. 2. Adicionalmente, foram registrados dois tipos de tubos vazios elaborados com grãos de areia, denominados de tubo 1 e 2 . Os tubos vazios foram contados neste estudo por indicarem a passagem de seus moradores pelo caranguejo. O tubo 1 apresentava semelhança com um tubo de Amphipoda, sendo provavelmente elaborado por uma das espécies analisadas no estudo. O tubo 2 possuía uma estrutura mais resistente em relação ao tubo 1 , pela quantidade proporcionalmente maior de areia e, portanto, é muito provável que pertença a Polychaeta. A ocorrência de uma colônia de tubos em um mesmo caranguejo foi considerada uma unidade devido à dificuldade na distinção dos tubos. Este procedimento também foi utilizado na análise dos organismos coloniais, como Bryozoa. 
No estudo da distribuição de freqüência de ocorrência de macroepizóicos e o tamanho dos caranguejos hospedeiros, estes tiveram a largura da carapaça ordenada em oito classes denominadas de A a $\mathrm{H}$, em ambos os sexos: $\mathrm{A}=0,00-9,95 \mathrm{~mm} ; \mathrm{B}=10,00-19,95$ $\mathrm{mm} ; \mathrm{C}=20,00-29,95 \mathrm{~mm} ; \mathrm{D}=30,00-39,95 \mathrm{~mm} ; \mathrm{E}=40,00$ $49,95 \mathrm{~mm} ; \mathrm{F}=50,00-59,95 \mathrm{~mm} ; \mathrm{G}=60,00-69,95 \mathrm{~mm}$ e $\mathrm{H}=70,00-79,95 \mathrm{~mm}$.

Todo material biológico foi tombado na Coleção de Crustacea, do Museu de História Natural do Capão do Imbuia, Curitiba, Paraná, sob os números 2.570 a 2.701.

\section{RESULTADOS}

No total, foram coletados 132 caranguejos, 49 na primeira etapa, todos com macroepizóicos e 83 na segunda, dos quais 72 sem e 11 com macroepizóicos.

Os macroepizóicos sésseis registrados foram: Calliactis tricolor (Lesueur, 1817) (Cnidaria, Anthozoa); Actiniaria (Cnidaria, Anthozoa); Arca sp. (Mollusca, Bivalvia); Ostreidae (Mollusca, Bivalvia); Acanthodesia tenuis (Desor, 1848) (Bryozoa); duas espécies de Gammaridea (Crustacea, Amphipoda); Cirripedia (Crustacea) e tubos 1 e 2.

Os macroepizóicos vágeis observados foram: Nereidae (Annelida, Polychaeta), Gastropoda (Mollusca), Caprellidea (Crustacea, Amphipoda) e Porcellanidae (Crustacea, Anomura). Dentre estes, Porcellanidae apresentou maior frequiência, sendo encontrado em cinco caranguejos.

Os caranguejos apresentaram uma amplitude de variação da largura da carapaça de $9,00 \mathrm{~mm}$ a 77,15 mm. Aqueles com macroepizoísmo mediram de $38,80 \mathrm{~mm}$ a $74,60 \mathrm{~mm}$ e portaram de 1 a 10 macroepizóicos por caranguejo, perfazendo um total de 180 macroepizóicos.

De uma forma geral, a densidade média esteve em torno de três macroepizóicos por caranguejo (Fig.1). Houve maior densidade na classe D, porém, como ela foi representada por apenas um caranguejo que portava seis macroepizóicos, não se pode interpretar que houve uma preferência dos macroepizóicos por esta classe. Já a classe $\mathrm{H}$ teve uma densidade baixa de um macroepizóico por

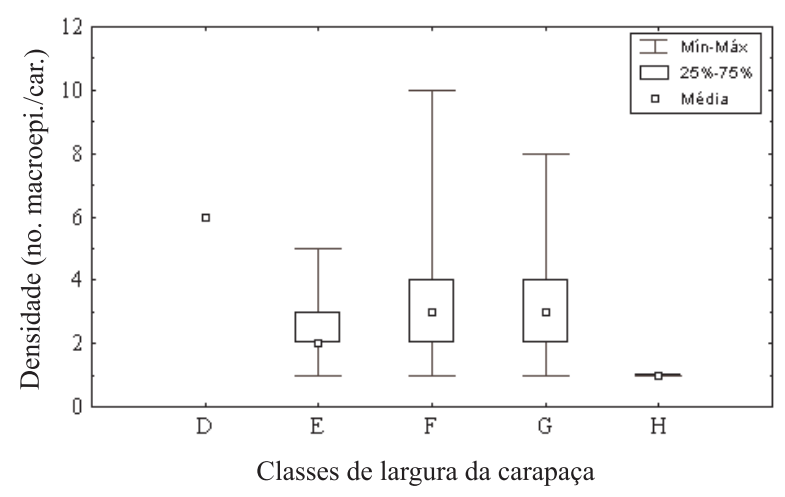

Fig. 1. Distribuição de densidade total dos macroepizóicos nas classes de largura da carapaça de Libinia ferreirae $(\mathrm{D}=30,00-39,95 \mathrm{~mm}$; $\mathrm{E}=40,00-49,95 \mathrm{~mm} ; \mathrm{F}=50,00-59,95 \mathrm{~mm} ; \mathrm{G}=60,00-69,95 \mathrm{~mm}$; $\mathrm{H}=70,00-79,95 \mathrm{~mm})$. caranguejo (macroepi./car.), sendo representada por dois macroepizóicos em dois caranguejos. A classe $\mathrm{G}$ teve uma densidade de 3,24 macroepi./car., seguida de F com 3,10 macroepi./car. e E com 2,43 macroepi./car.

A variação na densidade de cada macroepizóico nas classes de largura da carapaça foi de 0,04 a 3,33 macroepi./car. (Fig. 2). De uma maneira geral, os macroepizóicos ocorreram sem preferência por determinada classe de largura da carapaça, sendo $C$. tricolor representada por 68 dos 180 macroepizóicos. Entretanto, a classe F foi a única a apresentar todos os dez grupos macroepizóicos, enquanto as classes D e H tiveram 3 e 2 , respectivamente.

Nas amostragens feitas de agosto a outubro, foram obtidos 83 caranguejos, dos quais 11 apresentaram macroepizóicos, mostrando uma taxa de 13,25\% de macroepizoísmo (Fig. 3). É muito provável que essa taxa esteja relacionada à baixa quantidade de exemplares coletados nas classes F e G, e maior abundância nas classes de menor tamanho, ou seja, sem macroepizóicos. Os caranguejos desta amostragem estavam distribuídos nas classes de A a G, porém somente as classes E, F e G apresentaram macroepizóicos, numa porcentagem de $21,7 \%, 37,5 \%$ e $75,0 \%$, respectivamente. Isso demonstra que há um aumento na taxa de macroepizoísmo com o aumento do tamanho do caranguejo.

Dos 72 caranguejos sem macroepizóicos, ocorreram 40 fêmeas e 32 machos. Dentre os caranguejos com macroepizóicos, foram registrados 30 exemplares de cada sexo. O teste qui-quadrado mostrou que não há diferença na freqüência de ocorrência de epizoísmo nos dois sexos $\left(\chi^{2}=1,43\right.$; grau de liberdade $=1$; nível de significância $=$ $0,05)$. A abundância total de macroepizóicos também não variou significativamente entre os $\operatorname{sexos}\left(\chi^{2}=0,40\right.$; grau de liberdade $=1$; nível de significância $=0,05)$ : os machos portando 93 e as fêmeas 87 macroepizóicos. Machos apresentaram todos os dez grupos macroepizóicos, enquanto as fêmeas, nove (nestas faltou apenas uma espécie de Gammaridea). A densidade de cada grupo animal também não apresentou diferença significativa (teste do Qui-quadrado) entre os sexos, com exceção de Ostreidae e Cirripedia, que foram mais numerosos nas fêmeas e nos machos, respectivamente. Em função destes dados, machos e fêmeas foram tratados em conjunto em todas as análises de epizoísmo. Ambos os sexos tiveram uma densidade média de $C$. tricolor de aproximadamente uma anêmona por indivíduo.

Todas as 28 fêmeas ovígeras apresentaram macroepizoísmo, contra somente duas das 42 fêmeas nãoovígeras $(4,76 \%)$. As fêmeas ovígeras mostraram distribuição nas classes de $\mathrm{E}$ a $\mathrm{G}$, enquanto as nãoovígeras, de B a F (Fig. 4).

Os macroepizóicos foram registrados no rostro, na superfície dorsal da carapaça e nos pereiópodos 1 a 5 do lado esquerdo e 1 e 4 do lado direito do caranguejo (Fig. 5). A densidade média total na carapaça foi de 2,78 macroepi./car., enquanto as outras partes do corpo somaram uma densidade média de 0,22 macroepi./car. Somente a carapaça apresentou os dez grupos registrados, enquanto nos pereiópodos ocorreu apenas Bryozoa e Cirripedia e o rostro apresentou apenas Bryozoa. 


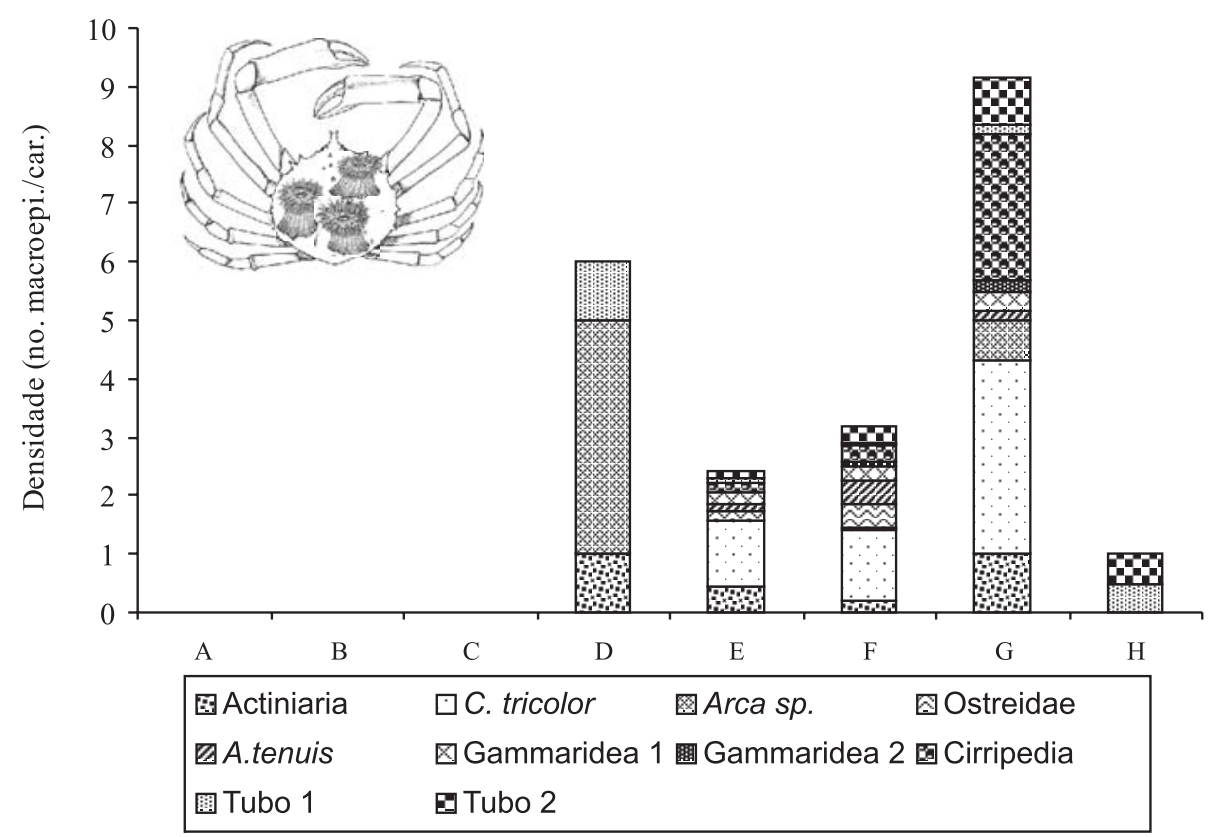

Fig. 2. Distribuição de densidade dos grupos macroepizóicos nas classes de largura da carapaça de Libinia ferreirae. Intervalo das classes na Fig. 1.

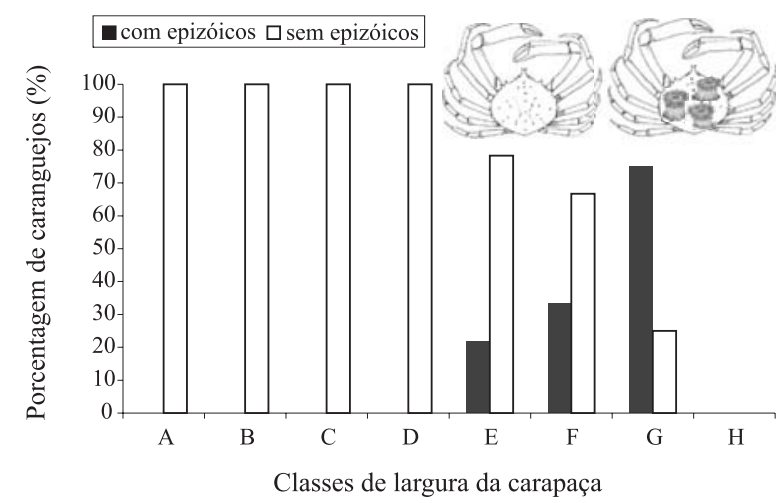

Fig. 3. Distribuição da freqüência relativa (\%) de Libinia ferreirae com e sem macroepizóicos nas classes de largura da carapaça, das amostras coletadas de agosto a outubro de 2004.
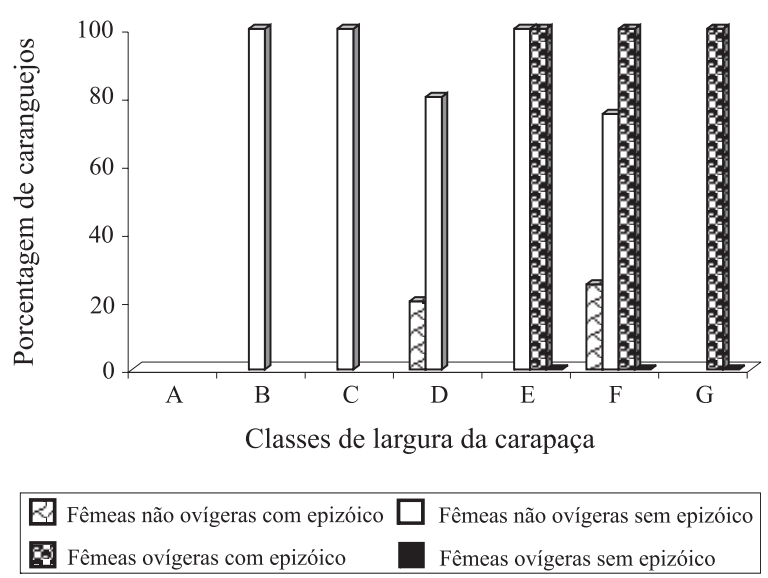

Fig. 4. Freqüência relativa (\%) das fêmeas ovígeras e não-ovígeras de Libinia ferreirae portadoras de macroepizoísmo.

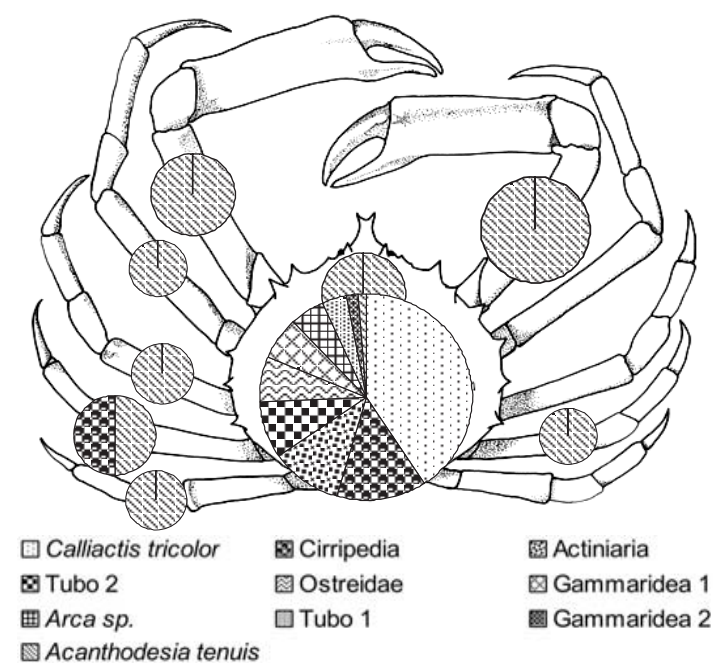

Fig. 5. Distribuição de densidade dos grupos macroepizóicos nas diversas partes do corpo do caranguejo Libinia ferreirae. O tamanho de cada gráfico (círculo) é proporcional à densidade total dos epizóicos.

\section{DISCUSSÃO}

A camuflagem por meio de fixação de epizóicos serve para tornar o caranguejo menos semelhante a um caranguejo. Alguns caranguejos parecem utilizar o epizoísmo para estocar alimentos, como Camposcia retusa Latreille, 1829, que prende pedaços de peixes em seus pereiópodos. Loxorhynchus crispatus raramente se alimenta de seus epizóicos e freqüentemente se decora com animais pouco predados, como esponjas e hidróides tóxicos. Outros o utilizam na caça de animais, como peixes que são atraídos pela morfologia diferenciada do caranguejo e são capturados de surpresa (WICKSTEN, 
1993). Vários membros de Majidae têm como predadores potenciais gaivotas, polvos, lagostas, tartarugas, caranguejos, lontras e peixes, contra os quais utilizam a camuflagem como forma de evitar a predação. $\mathrm{O}$ caranguejo L. ferreirae é predado por vários peixes (BosCHI et al., 1992) e é muito provável que também o seja por outros animais. Portanto, no caso dessa espécie, a hipótese mais provável é que ela use a camuflagem como forma de defesa e não de ataque, por ser um animal lento e pouco agressivo (observação pessoal).

A composição faunística do macroepizoísmo encontrada no presente estudo mostra a similaridade com outras espécies de caranguejos portadores de macroepizóicos. Com exceção de Porifera, Turbellaria e Ascidiacea, todos os grupos metazoários comuns neste tipo de associação estiveram representados em $L$. ferreirae (Mori \& Manconi, 1990; Abelló \& MACPHERSON, 1992; BECKer, 1996; Dick et al., 1998; FERNÁNDEZ et al., 1998).

Dos 60 caranguejos com macroepizóicos do presente estudo, 50 apresentaram pelo menos uma anêmona, perfazendo no total 86 dos 180 macroepizóicos encontrados. Esta freqüência pode ser considerada altamente importante, porque mais de $80 \%$ dos caranguejos com macroepizóicos carregam pelo menos uma anêmona. Os equivalentes ecológicos do litoral da Argentina, estudados por AcUÑA et al. (2003), corroboram a hipótese de que as anêmonas constituem os principais parceiros neste mutualismo. A vantagem desta associação para as anêmonas não parece ser o aproveitamento dos restos alimentares do hospedeiro, mas sim a disponibilização de um substrato biológico com possibilidade de migrar para diversos habitats e, assim, explorar novos recursos alimentares.

Os juvenis (1,5 mm a 32,6 mm de largura da carapaça) de L. ferreirae são encontrados em associação comensal com medusas (Nogueira Junior \& Haddad, 2005). Portanto, após abandonar este comensalismo, os caranguejos passam a viver no bentos e iniciar a fixação de macroepizóicos. Estes fatos indicam que L. ferreirae possui poucos mecanismos de defesa, como agilidade e quelas fortes. Exemplares criados em aquário mostram movimentos lentos (observação pessoal).

Segundo Wicksten (1980), Ascidia, Hydrozoa, Porifera e Actiniaria podem ser utilizados como fontes de defesa pelo caranguejo, por apresentarem substâncias tóxicas aos seus predadores. Portanto, é provável que a anêmona, além de ser usada como camuflagem, também possa servir como um mecanismo de defesa química dessa espécie.

Além da camuflagem, a maioria dos caranguejos da família Majidae possui o comportamento de se enterrar ou de se esconder no substrato, assim, somente os epizóicos são visualizados. A espécie estudada também possui esse comportamento, vivendo a maior parte do tempo enterrada na areia. De acordo com BAUER (1981), espécies que vivem em substratos de sedimento fino possuem menor probabilidade de serem colonizadas do que indivíduos de sedimentos mais grosseiros. O comportamento de se enterrar no sedimento reduz a possibilidade dos epizóicos se fixarem no hospedeiro, pois a abrasão é destrutiva, principalmente para os protozoários e macroepizóicos de porte delicado. Aparentemente, com exceção das anêmonas, os epizóicos são organismos indesejados pelo caranguejo, pois eles são fonte de enfermidades e de gasto de energia para a locomoção, além de possível competição (BECKER, 1996). A favor desta hipótese, as colônias do briozoário $A$. tenuis eram formadas de poucos zoóides, e o bivalve Arca sp. foi representado por exemplares de pequeno porte, mostrando que não havia condições para estabelecer colônias mais extensas ou indivíduos adultos.

Segundo Wicksten (1980) e Fernández et al. (1998), o padrão de epizoísmo e os organismos utilizados como epizóicos não diferem entre os sexos, exceto nas espécies em que o macho possui menos epizóicos que a fêmea. No presente estudo, também não houve uma diferença significativa entre a freqüência de machos e fêmeas com macroepizóicos, tampouco entre a abundância e a riqueza destes em cada sexo, corroborando a hipótese acima.

Vários estudos mostraram que fêmeas ovígeras possuem uma densidade de epizóicos maior do que as fêmeas não-ovígeras (JEFFries et al., 1992), como observado em L. ferreirae. Provavelmente, a presença de macroepizóicos traz vantagens a estas fêmeas no sentido de dar proteção aos ovos. Outra hipótese que deve ser considerada é o término do processo de muda das fêmeas ovígeras, sendo a carapaça mais velha do que nos estágios anteriores, facilitando o desenvolvimento dos epizóicos. Corrobora esta hipótese a maior frequiência de caranguejos sem macroepizóicos nas classes de menor largura da carapaça.

A menor freqüência de ocorrência de epizóicos nos caranguejos juvenis pode ser explicada pela alta frequiência de mudas dos mesmos, tornando difícil a fixação dos organismos epizóicos por causa da instabilidade do exoesqueleto (Mori \& MANCONI, 1990). De acordo com WiCKSTEN (1980), os caranguejos, após a segunda muda iniciam o processo de epizoísmo, aumentando a sua intensidade ao longo do tempo e abandonando esse comportamento somente após alcançarem um certo tamanho. É muito provável que o caranguejo maior não precise se camuflar para evitar a predação porque o seu tamanho basta para afastar o predador. Já Mori \& Manconi (1990), Abelló \& MACPHERSOn (1992), SHiELdS (1992), Dick et al. (1998) e FERNÁNDEZ et al. (1998) comentam que indivíduos maturos possuem densidade de epizóicos maior do que indivíduos juvenis. No presente estudo, a espécie apresentou macroepizoísmo a partir dos $38,80 \mathrm{~mm}$ e houve uma correlação direta entre a largura da carapaça do caranguejo e a frequiência e abundância dos respectivos macroepizóicos: quanto maior a área do exoesqueleto, maior a diversidade e abundância dos epizóicos. Entretanto, não houve um desaparecimento desse comportamento nos indivíduos maduros, como observado por WiCKSTEN (1980).

A diferença na distribuição dos organismos epizóicos na superfície do corpo do caranguejo está relacionada com a sua morfologia. Para FERNÁndEZ et al. (1998), a carapaça é uma área relativamente grande, bastante exposta e facilmente colonizada por organismos de diferentes tamanhos e formas. Por outro lado, a parte 
ventral do cefalotórax não precisa ser camuflada, além de ser menos acessível. O pereiópodo é a área menos favorável à colonização por causa da sua mobilidade, forma e reduzida superfície corporal. No presente estudo, a carapaça teve a maior abundância e riqueza de macroepizóicos, enquanto a parte ventral do cefalotórax não apresentou nenhum macroepizóico; somente os briozoários foram capazes de colonizar os pereiópodos de modo constante, corroborando a hipótese acima. O briozoário, além de ser incrustante, possui a forma e o tamanho do corpo melhor adaptados à vida em lugares inacessíveis, como o pereiópodo do caranguejo.

Agradecimentos. À Prof ${ }^{a} \operatorname{Dr}^{a}$ Maria Angélica Haddad, da Universidade Federal do Paraná, pela identificação de Calliactis tricolor. Ao biólogo Miodelli Nogueira Junior, mestrando em Zoologia da Universidade Federal do Paraná, pela doação de amostras de juvenis de Libinia ferreirae. Ao Prof. Dr. Emygdio Leite de Araújo Monteiro Filho, coordenador do Curso de Pósgraduação em Zoologia da UFPR, pela permissão no uso dos equipamentos. Ao CNPq pelo auxílio concedido na forma de taxa de banca à segunda autora.

\section{REFERÊNCIAS BIBLIOGRÁFICAS}

Abelló, P. \& Macpherson, E. 1992. Epibiosis and rhizocephalan infestation patterns in relation to the reproductive biology of Lithodes ferox (Filhol, 1885) (Anomura: Lithodidae). Journal of Crustacean Biology 12(4):561-570.

Acuña, F. H.; Excoffon, A. C. \& Scelzo, M. A. 2003. Mutualism between the sea anemone Antholoba achates (Drayton, 1846) (Cnidaria: Actiniaria: Actinostolidae) and the spider crab Libinia spinosa Milne-Edwards, 1834 (Crustacea: Decapoda: Majidae). Belgian Journal of Zoology 133(1):45-48.

BAUER, R. T. 1981. Grooming behavior and morphology in the decapod Crustacea. Journal of Crustacean Biology 1:153173

BECKER, K. 1996. Epibionts on carapaces of some malacostracans from the Gulf of Thailand. Journal of Crustacean Biology 16(1):92-104.

Boschi, E. E.; Fischbach, C. E. \& Iorio, M. I. 1992. Catálogo ilustrado de los crustáceos estomatópodos y decápodos marinos de Argentina. Frente Maritimo 10:7-94.

Dick, M. H.; Donaldson, W. E. \& Vining, I. W. 1998. Epibionts of the tanner crab Chionoecetes bairdi in the region of Kodiak Island, Alaska. Journal of Crustacean Biology 18(3):519-528.

Fernández, L.; Parapar, J.; González-Gurriarán, E. \& Muíño, R. 1998. Epibiosis and ornamental cover patterns of the spider crab Maja squinado on the glacian coast, Northwestern Spain: influence of behavioral and ecological characteristics of the host. Journal of Crustacean Biology 18(4):728-737.

Jefrries, W. B.; Voris, H. K. \& Poovachiranon, S. 1992. Age of the mangrove crab Scylla serrata at colonization by stalked barnacles of the genus Octolasmis. Biological Bulletin 182:188-194.

KILAR, J. A. \& Lou, R. M. 1986. The subtleties of camouflage and dietary preference of the decorator crab, Microphrys bicornutus Latreille (Decapoda: Brachyura). Journal of experimental marine biology and ecology 101(1-2):143-160.

Melo, G. S. 1996. Manual de identificação dos Brachyura (caranguejos e siris) do litoral brasileiro. São Paulo, Plêiade/FAPESP. 260p.

Mori, M. \& Manconi, R. 1990. Macroepizoites associated with Paromola cuvieri (Risso, 1816) (Decapoda, Homolidae) of the Ligurian Sea. Crustaceana 58(2):124-129.

Nogueira Junior, M. \& HAdDAd, M.A. 2005. Lychnorhiza lucerna (Scyphozoa, Rhizostomeae) and Libinia ferreirae Brito Capello (Brachyura, Majidae) association in southern Brasil. Revista Brasileira de Zoologia 22(4):908-912.

Shields, J. D. 1992. Parasites and symbionts of the crab Portunus pelagicus from Moreton Bay, Eastern Australia. Journal of Crustacean Biology 12(1):94-100.

Wicksten, M. K. 1980. Decorator crabs. Scientific American 242(2): $116-122$.

1993. A review and a model of decorating behavior in spider crabs (Decapoda, Brachyura, Majidae). Crustaceana 64:314-325.

Williams, R. \& Moyse, J. 1988. Ocurrence, distribution and orientation of Poecilasma kaempferi Darwin (Cirripedia: Pedunculata) epizoic on Neolithodes grimaldi Milne-Edwards and Bouvier (Decapoda: Anomura) in the Northeast Atlantic. Journal of Crustacean Biology 8(2):177-186.

WILSON, R. 1987. Substrate selection and decorating behavior in Acanthonyx petiveri related to exoskeleton color (Brachyura, Majidae). Crustaceana 52(2):135-140. 